\title{
Os efeitos da música em biomarcadores de estresse, imunológicos e comportamentais em portadores do espectro autista
}

\author{
The effects of music in stress, immunological and behavior \\ biomarkers in autism spectrum disorder
}

Juliane Neves Fiorezi, ${ }^{1}$ Silvia Isabel Rech Franke,, Daniel Prá, ${ }^{1}$ Edna Linhares Garcia, ${ }^{1}$ Jane Dagmar Pollo Renner ${ }^{-1}$

'Universidade de Santa Cruz do Sul (Unisc), Santa Cruz do Sul, RS, Brasil.

Recebido em: 01/10/2017 / Aceito em: 21/12/2017 / Publicado em: 30/12/2017

julianefiorezi@gmail.com

\section{RESUMO}

A utilização da Musicoterapia em portadores do Transtorno do Espectro Autista (TEA) teve início na década de 60 e mostrou promover benefícios, tais como: diminuição de crises comportamentais, diminuição de resistência ao tratamento, melhora nos relacionamentos interpessoais, aquisição de liberdade expressiva, aquisição da melhora vocal, melhora na comunicação, aquisição de confiança verbal e vocal, aquisição de ordem rítmica e melhora na produção da fala e mutualidade. Objetivo: embora os resultados em nível comunicacional sejam de amplo conhecimento e na busca por compreender o impacto da música nos biomarcadores imunológicos e de estresse nesses indivíduos, o presente artigo tem por objetivo apresentar uma breve revisão dos estudos recentes acerca dessa temática. Método: foram utilizadas ferramentas de busca nas bases de dados PubMed, Lilacs, Cochrane e Scielo. A busca foi realizada em artigos publicados em português e inglês, por meio dos descritores "imunoglobulina", "cortisol salivar", "dano celular", "musicoterapia" e "autismo". Resultado: por meio da pesquisa foi possível constatar a influência da música como um meio complementar no cuidado de portadores do TEA, enquanto instrumento de promoção da saúde e melhoria de qualidade de vida desses indivíduos. Considerações finais: embora os estudos apontem os benefícios da música em portadores do TEA, sugere-se que sejam realizadas mais pesquisas nesse campo, sobretudo no Brasil. Portanto, o presente artigo se propõe como base teórica para uma posterior pesquisa-intervenção a fim de verificar os possíveis efeitos provocados por diferentes tipos de escuta musical sobre os indicadores de cortisol salivar, imunoglobulina A e dano celular de células epiteliais, bem como nos aspectos comportamentais, em crianças portadoras do Transtorno do Espectro Autista. A segunda fase da pesquisa já está em desenvolvimento, por meio do Programa de Pós-Graduação em Promoção da Saúde (Mestrado - UNISC) e seus resultados serão conhecidos em 2018.

Palavras-chave: Imunoglobulina; Cortisol Salivar; Dano Celular; Musicoterapia; Autismo.

\section{ABSTRACT}

The use of Music Therapy in patients with Autism Spectrum Disorder (ASD) began in the 60s and showed benefits such as: reduction of behavioral crises, reduction of resistance to treatment, improvement in interpersonal relationships, acquisition of expressive freedom, acquisition of vocal improvement, improvement in communication, acquisition of verbal and vocal confidence, acquisition of rhythmic order and improvement in speech production and mutuality. Objective: although the results at the communicational level are widely known and in the quest to understand the impact of music on immunological and stress biomarkers in these individuals, this article aims to present a brief review of the recent studies about this subject. Method: search tools were used in PubMed, Lilacs, Cochrane and Scielo databases. The search was conducted in articles published in Portuguese and English, using the descriptors "immunoglobulin", "salivary cortisol", "cell damage", "music therapy" and "autism". Results: through the research it was possible to verify the influence of music 
as a complementary means of caring for ASD patients, as an instrument to promote health and improve the quality of life of these individuals. Closing remarks: although the studies point out the benefits of music in patients with $A S D$, it is suggested that more research be done in this field, especially in Brazil. Therefore, the present article is proposed as a theoretical basis for a subsequent intervention research in order to verify the possible effects caused by different types of musical listening on the salivary cortisol, immunoglobulin $A$ and cellular epithelial cell damage indicators, as well as on the aspects behavioral disorders in children with ASD. The second phase of the research is already under development, through the Post-Graduate Program in Health Promotion (Master's Degree - UNISC) and its results will be known in 2018.

Keywords: Immunoglobulin; Salivary Cortisol; Ccell Damage; Music Therapy; Aautism.

\section{INTRODUÇ̃̃O}

A interface entre música e saúde tem o seu primeiro registro oficial em 1914, quando a utilização da música em centros cirúrgicos promoveu a diminuição do nível do estresse, bem como uma maior tolerância à indução anestésica em pacientes em situação pré-operatória. Outro marco na utilização da música, como meio de intervenção potencial à saúde do homem, ocorreu durante a Segunda Guerra Mundial, quando enfermeiros e médicos utilizaram a música, por meio de instrumentos musicais para aliviar a tensão, a dor e o abatimento psicológico dos soldados que se encontravam nos espaços de cuidado dos campos de batalha. ${ }^{1}$

Desde então, os históricos médicos acerca da utilização da música em intervenções hospitalares foram precedentes fundamentais para o desenvolvimento da Musicoterapia (MT) enquanto disciplina autônoma, complementar e interdisciplinar às demais ciências da vida. Em sua definição, assume o ambiente médico enquanto espaço profissional com o escopo de otimizar a qualidade de vida e melhorar a saúde e bem-estar físico, social, comunicacional, emocional, intelectual e espiritual do paciente. ${ }^{2}$

Segundo o autor supracitado, a utilização da MT em portadores do Transtorno do Espectro Autista (TEA) teve início na década de 60 e mostrou promover benefícios, tais como: diminuição de crises comportamentais, diminuição de resistência ao tratamento, melhora nos relacionamentos interpessoais, aquisição de liberdade expressiva, aquisição da melhora vocal, melhora na comunicação, aquisição de confiança verbal e vocal, aquisição de ordem rítmica e melhora na produção da fala e mutualidade.

Geretsegger et al. ${ }^{3}$ reforçam que a MT em portadores de TEA contribui para a melhoria na interação social, comunicação verbal e reciprocidade socioemocional, além de aumento das habilidades de adaptação social e na promoção da qualidade da relação entre pais e filhos. Ademais, Whipple ${ }^{4}$ diz que essa prática inclui benefícios para o autocuidado e lazer, bem como diminuição de comportamentos inadequados ou estereotipias.

Por outro lado, a busca por marcadores bioquími- cos no diagnóstico e tratamento de doenças vem ocupando parte das pesquisas que envolvem a prevenção e/ou promoção da saúde. Ao que se refere à busca de biomarcadores de eficácia no tratamento do TEA, é possível encontrar dois principais marcadores, os níveis de imunoglobulina A ( $\lg A)$ e o cortisol salivar.

Achados apontam que em indivíduos autistas, quando comparados com seus pares considerados normais, existe diferenciação em alguns biomarcadores, sobretudo nos aspectos relacionados a fatores imunológicos e de estresse, sugerindo que os portadores de TEA são mais propensos à deficiência imunológica, bem como elevado nível de resposta endócrina a estressores externos. ${ }^{5,6}$ Evidências também foram encontradas na relação entre os marcadores bioquímicos e as estereotipias comportamentais, de movimento, e também na capacidade de atenção e comunicação interpessoal, sendo esta última considerada um dos principais fatores estressores que desencadeiam o comportamento autista. ${ }^{7}$

Além da resposta imunológica alterada em indivíduos com TEA, existem estudos que buscaram verificar a relação entre disfunções celulares e o desenvolvimento do TEA, considerando a avaliação celular como um biomarcador de saúde nesses indivíduos. Nos referidos estudos, são destacados o estresse oxidativo, disfunções mitocondriais e os danos celulares associados ao autismo. ${ }^{8,9} \mathrm{~A}$ fim de compreender de que modo a música pode contribuir para a melhoria da qualidade de vida desses indivíduos, em um primeiro momento, buscou-se verificar, por meio de uma breve revisão bibliográfica, como a escuta musical pode impactar nos índices de $\lg \mathrm{A}$, cortisol salivar e dano celular. Entretanto, apesar do vasto acervo de pesquisas que relacionam o autismo a esses marcadores, a influência da música em biomarcadores com crianças autistas mostrou-se escassa. ${ }^{10}$ Além disso, tem-se conhecimento dos impactos diretos na diminuição do cortisol salivar e aumento da $\lg A$ em indivíduos saudáveis, quando expostos à diversas atividades de escuta e fazer musical, ${ }^{11}$ porém, é pouco avaliado o seu efeito em portadores de TEA, sobretudo, quando busca-se evidenciar o dano celular.

\section{MÉTODO}

O presente artigo apresenta uma revisão bibliográfica em base aos estudos recentes que apontam a influência da música em biomarcadores imunológicos e de estresse, bem como benefícios no âmbito comportamental de indivíduos portadores do TEA. Foram utilizadas ferramentas de busca nas bases de dados PubMed, Lilacs, Cochrane e Scielo. A busca foi realizada em artigos publicados em português e inglês, por meio dos descritores "imunoglobulina", "cortisol salivar", "dano celular", "musicoterapia" e "autismo".

\section{RESULTADOS}

A seguir apresentam-se os resultados da busca realizada acerca da temática abordada no presente artigo. Em primeiro lugar apresentam-se os estudos relativos aos biomarcadores de imunidade, estresse e dano celular relacionados ao TEA. 
Tabela 1 - Estudos encontrados acerca do marcadores imunológicos e de estresse relacionados ao TEA.

\begin{tabular}{|c|c|c|}
\hline Autor & Marcador & Teste Shapiro-Wilk \\
\hline Spiroski et al. ${ }^{12}$ & Imunológico & $\begin{array}{l}\text { Os baixos níveis de IgA são frequentemente encontrados em crianças com } \\
\text { TEA, quando comparados ao seus pais, bem como aos seus irmãos e irmãs } \\
\text { saudáveis provenientes dos mesmos genitores. }\end{array}$ \\
\hline $\begin{array}{l}\text { Onore, Careaga } \\
\text { e Ashwooda }\end{array}$ & Imunológico & $\begin{array}{l}\text { As respostas imunitárias disfuncionais estão associadas a maiores transtornos } \\
\text { nos comportamentos característicos do TEA, como déficits nas interações } \\
\text { sociais e na comunicação. }\end{array}$ \\
\hline Bjorklund et al. ${ }^{5}$ & Imunológico & $\begin{array}{l}\text { Respostas imunes alteradas em indivíduos diagnosticados com TEA, sendo } \\
\text { frequente o aparecimento de perda de tolerância imunológica, alergias e tran- } \\
\text { storno autoimunes não diagnosticados. }\end{array}$ \\
\hline Wasilewska et al. ${ }^{13}$ & Imunológico & $\begin{array}{l}\text { O diagnóstico positivo de TEA esteve relacionado à IgA em crianças de três a } \\
\text { seis anos de idade. }\end{array}$ \\
\hline Hsiao e Patterson ${ }^{14}$ & Imunológico & $\begin{array}{l}\text { As respostas imunológicas alteradas estão diretamente relacionadas aos distúr- } \\
\text { bios do desenvolvimento neurológico, sendo um deles o aparecimento do TEA. }\end{array}$ \\
\hline Danese e Lewis ${ }^{15}$ & Imunológico & $\begin{array}{l}\text { O estresse na infância provoca a inflamação posterior, e há analogias mar- } \\
\text { cantes entre os correlatos neurobiológicos do estresse infantil e da inflamação. }\end{array}$ \\
\hline Tordjman et al. ${ }^{16}$ & Estresse & $\begin{array}{l}\text { Nos portadores de autismo os níveis de cortisol são mais elevados quando } \\
\text { expostos a estressores/ existe uma relação entre os níveis elevados de cortisol } \\
\text { e as deficiências na interação social e linguagem verbal, bem como em funções } \\
\text { cognitivas, quando comparados a crianças com níveis de desenvolvimento } \\
\text { considerados normais. }\end{array}$ \\
\hline Ogawa et al. ${ }^{17}$ & Estresse & $\begin{array}{l}\text { Nos portadores de autismo os níveis de cortisol são mais elevados quando } \\
\text { expostos a estressores/ existe uma relação entre os níveis elevados de cortisol } \\
\text { e as deficiências na interação social e linguagem verbal, bem como em funções } \\
\text { cognitivas, quando comparados a crianças com níveis de desenvolvimento } \\
\text { considerados normais. }\end{array}$ \\
\hline Rance et al. ${ }^{18}$ & Estresse & $\begin{array}{l}\text { Existe interrelação entre melhora na comunicação e a redução dos níveis de } \\
\text { cortisol salivar. }\end{array}$ \\
\hline $\begin{array}{l}\text { Thomas et al. }{ }^{19} \\
\text { François et al. }{ }^{20} \\
\text { Lee et al. }\end{array}$ & Dano celular & $\begin{array}{l}\text { Em pessoas que apresentam distúrbios neurológicos, foram encontrados } \\
\text { estudos aplicados em crianças com Síndrome de Down, em pacientes com } \\
\text { doenças neurodegenerativas e em pessoas com comprometimentos cognitivos, } \\
\text { indicando relação direta entre a instabilidade genômica e as referidas anoma- } \\
\text { lias, quando em comparação com pessoas normais. }\end{array}$ \\
\hline Main et al. ${ }^{22}$ & Dano celular & $\begin{array}{l}\text { Crianças com autismo são mais propensas aos danos celulares decorrentes da } \\
\text { exposição de condições de estresse oxidativo, quando comparadas com pares } \\
\text { de irmãos que não possuem o transtorno. }\end{array}$ \\
\hline $\begin{array}{l}\text { Markkanen, Meyer e } \\
\text { Dianov }^{8}\end{array}$ & Dano celular & $\begin{array}{l}\text { Reforçam a associação entre o estresse oxidativo e o TEA, sugerindo que a } \\
\text { disfunção endócrina tem causa em uma deficiência de regulação das funções } \\
\text { do cerebelo e do córtex frontal. Para os autores, o estresse oxidativo desenca- } \\
\text { deia a resposta de estresse celular. }\end{array}$ \\
\hline
\end{tabular}

É importante salientar que os biomarcadores no diagnóstico de autismo ainda estão em desenvolvimento, entretanto, dentre os marcadores endócrinos e imunológicos associados ao autismo, pesquisas apontam a $\lg \mathrm{A}$, o cortisol salivar, o estresse oxidativo e a anormalidade mitocondriais como fatores que impactam diretamente na morte celular dos tecidos epiteliais desses indivíduos. ${ }^{12,23-25}$

A $\lg A$ é um composto constituído de glicoproteínas e age como agente protetor do organismo em resposta a invasão de microrganismos, como vírus e bactérias, inibindo os mesmos de instalarem-se nas mucosas epiteliais. Sua deficiência no organismo humano é uma das imunodeficiências congênitas mais conhecidas, apresentando alta prevalência - em média 1:700 nascidos vivos. ${ }^{26}$

Segundo os autores supracitados, dentre as doenças e morbidades relacionadas à deficiência da $\lg \mathrm{A}$ encontram-se infecções graves (pneumonias, bronquiectasias e meningite), diarreia crônica associada, hiperplasia linfoide, má absorção intestinal e déficit de crescimento e alergias alimentares como hipersen- sibilidade ao glúten e outros alimentos. O tratamento das doenças de deficiência da IgA ocorre por meio da administração de antibióticos e, segundo os autores, é contraindicado o tratamento de reposição de imunoglobulinas por meio de procedimentos intravenosos e intramusculares, por conterem baixa concentração de imunoglobulinas, bem como risco de indução a reações anafiláticas.

A relação entre indivíduos diagnosticados com o TEA e as concentrações de imunoglobulina A são mencionados em alguns estudos. Spiroski et al. ${ }^{12}$ relatam a hipótese de que os baixos níveis de $\lg A$ são frequentemente encontrados em crianças com TEA, quando comparados ao seus pais, bem como aos seus irmãos e irmãs saudáveis provenientes dos mesmos genitores. Segundo Onore, Careaga e Ashwooda, ${ }^{7}$ as respostas imunitárias disfuncionais estão associadas a maiores transtornos nos comportamentos característicos do TEA, como déficits nas interações sociais e na comunicação.

Conforme Bjorklund et al., ${ }^{5}$ observam-se respostas imunes alteradas em indivíduos diagnosticados com 
TEA, sendo frequente o aparecimento de perda de tolerância imunológica, alergias e transtorno autoimunes não diagnosticados. Wasilewska et al., ${ }^{13}$ na tentativa de comprovar a correlação entre diagnóstico de autismo e as baixas concentrações de $\lg \mathrm{A}$, evidenciaram que o diagnóstico positivo esteve relacionado à $\lg \mathrm{A}$ em crianças de três a seis anos de idade.

Portanto, pesquisas como a de Hsiao e Patterson ${ }^{14}$ demonstram frequente associação entre indivíduos diagnosticados com TEA e a presença de menor resposta imunológica natural biológica do organismo, sendo, então, evidenciado por meio do marcador $\lg \mathrm{A}$. Nesse aspecto, os pesquisadores citados inferem que as respostas imunológicas alteradas estão diretamente relacionadas aos distúrbios do desenvolvimento neurológico, sendo um deles o aparecimento do TEA.

As pesquisas relativas às avaliações do cortisol salivar e sua associação ao autismo, nos últimos cinco anos, apresentam-se em maior número, demonstrando evidências importantes para a compreensão da dinâmica biológica dos portadores de TEA. Em sua maioria, estão associados ao desenvolvimento do estresse e ansiedade, sendo a análise do cortisol salivar um importante indicador do nível de estresse em autistas. Assim, percebe-se a elevação dos índices de cortisol salivar em indivíduos portadores de TEA expostos à interação social. ${ }^{6}$

Frequentemente utilizado como biomarcador do estresse, o cortisol salivar é um reflexo biológico do estresse, sendo utilizado frequentemente em pesquisas de associação entre autopercepção do estresse e os níveis de cortisol salivar. ${ }^{27,28}$ Sua produção acontece no segundo momento de reação ao estresse pelo acionamento do eixo hipotálamo-hipófise-adrenal (HPAA). Seus níveis indicam a presença de cortisol livre em circulação no organismo e pode ser coletado por diversas metodologias, entretanto, sua extração por meio da saliva tem sido mais frequentemente utilizada, por envolver um procedimento não invasivo e de menor custo. ${ }^{29}$

O sistema responsável pela secreção do cortisol salivar é o eixo HPAA, ativado de modo natural pelo ciclo circadiano; tem como função preparar o organismo para as atividades do dia a dia. Segundo El-Farhan et $\mathrm{al}^{30}{ }^{30}$ esse hormônio é produzido no córtex adrenal e sua secreção é controlada pela liberação da adrenocorticotrofina (ACTH), que por sua vez é regulada pela corticotrofina $(\mathrm{CRH})$. Nesse sistema endócrino, o estresse atua sobre o hipotálamo, aumentando a produção de $\mathrm{CRH}$ e, por consequência, ocorre o feedback negativo do cortisol.

Tordjman et al. ${ }^{16}$ e Ogawa et al. ${ }^{17}$ evidenciaram que os níveis de cortisol são mais elevados nos portadores de autismo quando expostos a estressores e, demonstraram, também, que existe uma relação entre os níveis elevados de cortisol e as deficiências na interação social e linguagem verbal, bem como em funções cognitivas, quando comparados a crianças com níveis de desenvolvimento considerados normais. $O$ resultado da pesquisa desses autores citados indica um nível maior de ansiedade e estresse em crianças portadoras de TEA, dada a especificidade do transtorno relacionar-se diretamente à dificuldade de interação social. Novamente a interrelação entre melhora na comunicação e a redução dos níveis de cortisol salivar é relatado por Rance et al., ${ }^{18}$ quando apontam que o uso de sistemas de melhoria na audição influenciou na melhor qualidade de interação e por consequência redução nos níveis de cortisol.

Esse efeito ocorre devido ao cortisol ser um hormônio produzido em resposta ao estresse, sendo essencial para a manutenção do bem-estar e a saúde do ser humano. A relação entre o cérebro e resposta imunológica está diretamente relacionada, influenciando-se mutuamente. Segundo Danese e Lewis (p.100), ${ }^{15}$ em seu estudo realizado com crianças diagnosticadas com estresse precoce informam que

a interação bidirecional entre o cérebro e o sistema imunológico torna possível que os estressores psicossociais da infância afetem o desenvolvimento do sistema imunológico, o que, por sua vez, pode afetar o desenvolvimento do cérebro e seu funcionamento a longo prazo [...] O estresse na infância provoca a inflamação posterior, e há analogias marcantes entre os correlatos neurobiológicos do estresse infantil e da inflamação.

Sob este aspecto, a relação entre cortisol e a resposta imunológica no organismo ocorre de forma inversamente proporcional, pois a secreção do cortisol inibe a atuação da imunoglobulina e como consequência reduz a resposta imunológica do organismo. Essa relação acontece por causa dos componentes bioquímicos desses hormônios, conforme demonstra El-Farhan et al (p. 312), ${ }^{30}$

o cortisol tem efeitos anti-inflamatórios e imunossupressores. Reduz as contagens de linfócitos circulantes por redistribuição para o baço, linfonodos e medula óssea. Inibe a síntese de imunoglobulinas, induz a apoptose dos linfócitos e previne a produção de citoquinas inflamatórias (por exemplo, interleucina-1, 2, 6, produção de fator de necrose tumoral (TNF), interferão- $\gamma$ ) através da inibição do fator nuclear kappa $B$ (NF-kB). A diferenciação de monócitos em macrófagos e a posterior função de macrófagos são inibidas pelo cortisol, e a inflamação local é suprimida pela redução da produção de histamina e pela síntese de prostaglandina prejudicada.

Complementando os resultados apresentados acima, a seguir serão apresentadas pesquisas que envolvem o dano celular em portadores de TEA.

\section{Dano celular em portadores de TEA}

Outro biomarcador utilizado para averiguação das condições de saúde endócrina e celular em indivíduos é a análise de citomas de células (BMCyt). Trata-se de uma abordagem pouco invasiva que tem como possibilidades a avaliação de danos no DNA, proliferação celular, diferenciação celular e morte celular. ${ }^{31,32}$ A utilização do BMCyt demonstrou-se um importante marcador quando relacionado a pesquisas envolvendo a análise dos danos celulares causados por agentes genotóxicos, características da nutrição e fatores relacionados ao estilo de vida, tornando-se também um importante aliado à prática clínica de diferentes doenças, dentre elas o câncer. ${ }^{33}$

A instabilidade genômica se caracteriza pela mutação celular, quando existe danos no DNA. Fatores genéticos, hormonais, nutricionais, de sexo e idade e exposição a agentes de contaminação, a exemplo de poluição, elementos químicos e radioativos, podem 
estar associados a esses danos. Segundo Main ${ }^{22}$ pode ser causada por defeitos nos genes requisitados para a replicação e/ou reparo do DNA, mitose, controle do ciclo celular ou ainda, por decorrência da deficiência de micronutrientes necessários ao metabolismo do DNA.

Como as células estão constantemente expos tas a agentes potencialmente prejudiciais, eles desenvolveram inúmeras vias de reparo do DNA que entram em jogo de acordo com o tipo de dano do DNA. Se o dano do DNA é irreparável, a célula pode sofrer morte celular programada ou sobreviver como uma célula geneticamente aberrante (p. 27). ${ }^{22}$

Em relação as pessoas que apresentam distúrbios neurológicos foram encontrados estudos aplicados em crianças com Síndrome de Down, em pacientes com doenças neurodegenerativas e em pessoas com comprometimentos cognitivos, indicando relação direta entre a instabilidade genômica e as referidas anomalias, quando em comparação com pessoas normais. ${ }^{19-21}$ Também foram realizados estudo em pessoas expostas a metais pesados e indivíduos acometidos por distúrbios alimentares como anorexia e bulimia nervosa. ${ }^{34,35}$

Apesar de ser um biomarcador eficaz para a verificação dos efeitos da exposição de elementos danosos, tanto em âmbito biológico ou endógeno quanto exógenos - no caso de exposição a poluentes ou metais - os estudos que envolvem a análise de citoma de células em portadores de TEA ainda são escassos em comparação aos demais marcadores relatados anteriormente, quais sejam, $\lg \mathrm{A}$ e o cortisol salivar. Entretanto, o estudo de Main et al. ${ }^{22}$ apontou que crianças com autismo são mais propensas aos danos celulares decorrentes da exposição de condições de estresse oxidativo, quando comparadas com pares de irmãos que não possuiam o transtorno.

Ademais, Markkanen, Meyer e Dianov ${ }^{8}$ reforçaram a associação entre o estresse oxidativo e o TEA, sugerindo que a disfunção endócrina tem causa em uma deficiência de regulação das funções do cerebelo e do córtex frontal. Para os autores, o estresse oxidativo desencadeia a resposta de estresse celular. A resposta imunológica decorrente do dano celular é discutida por Nadak e Schumacher ${ }^{36}$ que descreveram a relação de reparação ativada pelo organismo em resposta ao dano celular. Portanto, apontaram a relação entre dano celular e ativação do sistema imunológico.

Além desses achados os autores também salientam que existe uma lacuna de pesquisas relativas a associação entre autismo e dano celular e, portanto, sugerem o desenvolvimento de pesquisas que relacionem a instabilidade genômica ao desenvolvimento do TEA.

\section{DISCUSSÃO}

O interesse pelo conhecimento dos efeitos da música e de seus elementos no ser humano tem revolucionado a pesquisa científica quanto ao seu potencial em promover saúde. ${ }^{11} \mathrm{~A}$ interação entre a produção e a escuta musical vem gradativamente sendo interrelacionada a biomarcadores, com o principal objetivo de verificar o efeito somático da produção musical na biodinâmica humana. Os estudos versam a respeito dos efeitos em nível psicológico, fisiológico, neurológico e endócrino da escuta e do fazer musical e para fins de reforço ao objeto do presente artigo, será descrito o estado da arte em relação aos aspectos endócrinos e psicológicos relacionados à escuta musical.

O estudo, realizado por Charnetski e Brennan, ${ }^{37}$ objetivou avaliar a relação entre a estimulação musical e a secreção de $\lg \mathrm{A}$ em estudantes. O estudo comparou dois momentos de exposição em aula, no primeiro deles assistiram aula sem música de fundo e no segundo momento estavam expostos a música ambiente. Dois tipos de música também foram utilizados, sendo para um grupo música de rádio e no outro "Smooth Jazz". As evidências apontaram que no grupo que ouviu música de rádio houve acréscimo de $7,2 \%$ nos índices de $\lg \mathrm{A}$, no grupo que ouviu "Smooth Jazz" aumentou 14,1\% e no grupo controle, que estavam em ambiente silencioso, diminuiu em $9 \%$.

Uma pesquisa realizada com estudantes universitários, no Japão, evidenciou respostas endócrinas significativas da escuta musical e os efeitos dos diferentes estilos musicais também apresentaram respostas diferenciadas. Os autores avaliaram os índices de $\lg A$, morte celular, número de linfócitos $\mathrm{T} C \mathrm{CD} 4+, \mathrm{CD} 8+$, CD6+, além dos índices de dopamina, norepinefrina e epinefrina. Os resultados demonstraram que a audição das músicas relaxantes aumentaram a sensação de bem-estar e as músicas mais agitadas elevaram os níveis de norepinefrina, por outro lado, a morte celular esteve associada ao silêncio. ${ }^{38}$

Fancourt, Ockelford e Belai ${ }^{11}$ fizeram uma revisão sistemática acerca dos efeitos da música e apontaram cinco principais categorias: respostas psicológicas, fisiológicas, neurológicas, endócrinas e imunológicas. Em relação às respostas endócrinas, foi evidenciado reduções significativas nos níveis de cortisol, tanto pela escuta musical quanto pelo fazer musical ativo. Quanto ao estilo musical, apontaram a música relaxante como principal ativadora dos resultados benéficos para esse biomarcador. A respeito da resposta imunológica, oito dos nove estudos relatados, apresentaram aumento da secreção de $\lg A$ a partir da estimulação musical.

A correlação de eficácia comparada entre músicas selecionadas pelos pesquisadores participantes da referida revisão sistemática e músicas selecionadas pelos participantes, não demonstraram evidencias claras, sendo aconselhado, pelos próprios autores do estudo, que fossem realizadas mais pesquisas a fim de esclarecer quais são as variáveis musicais responsáveis pelas alterações nos biomarcadores, pois apenas um estudo, dentre os selecionados, apresentou a comparação entre a escolha musical do experimentador e a escolha do sujeito da pesquisa.

Os efeitos benéficos da música em biomarcadores já foram avaliados positivamente em pacientes com Alzhaimer. ${ }^{39}$ Entretanto, são escassas as pesquisas que aliam os efeitos da música em biomarcadores com portadores do TEA. Sabendo que esses pacientes são mais propensos aos índices elevados de cortisol, dano celular e baixa produção de $\lg \mathrm{A}$, apresenta-se então um amplo campo de investigação.

Para Pegoraro, ${ }^{40}$ existe uma importante influência da música no sistema neuropsicológico da criança autista, inferindo que a mesma interfere significativamente 
em áreas neuronais relacionadas à interação, psicomotricidade e linguagem, sendo uma importante aliada em áreas relativas ao estímulo do desenvolvimento global da criança.

Além das questões antropológicas e sociais relacionadas ao entendimento da música enquanto produto final, questões mais específicas ligadas ao processamento de seus atributos componentes devem ser mencionados. A percepção da música se trata do processamento de ondas sonoras dentro de uma linguagem musical, e deste modo está pautada na percepção sonora de aspectos físicos do som. Em termos neuropsicológicos, isso significa que qualquer música pode ser decomposta em seus atributos principais para que seja processada externa (por meio dos órgãos sensórios respectivos) e internamente (por meio do encéfalo) pelo Sistema Nervoso Central (SNC). Dessa forma, a Neurociência, enquanto área que se preocupa com as relações entre SNC e os aspectos sensoriais, perceptivos e cognitivos tem se destacado ao longo dos anos, desde os primeiros estudos experimentais acerca da música, na formulação de modelos de compreensão do processamento musical. ${ }^{41-45}$

Compreendendo o TEA como um distúrbio decorrente das deficiências localizadas no funcionamento neuronal, infere-se que a música, enquanto elemento a ser codificado no cérebro, pode ativar as áreas que coordenam a liberação dos hormônios responsáveis pela saúde e bem-estar dos indivíduos. Portanto, faz-se necessário empreender mais pesquisas que correlacionem esses dois aspectos, a música e a correlação psiconeuroimunológica.

\section{Impacto da música nos aspectos comportamentais em portadores de TEA}

Os distúrbios de comunicação e sociais são encontrados de modo frequente em portadores de TEA. Portanto, o autismo pode ser definido como um transtorno decorrente de distúrbios no desenvolvimento neurológico, que impactam em dificuldades relacionados a comportamento interpessoais e na comunicação, bem como ênfase em comportamentos repetitivos e interesse restrito. ${ }^{46} \mathrm{Na}$ Classificação Estatística Internacional de Doenças e Problemas Relacionados com a Saúde (CID-10), enquadra-se nos distúrbios relativos aos transtornos globais do desenvolvimento.

Esse distúrbio promove comprometimento do tipo sociocomunicativo combinado a movimentos estereotipados e repetitivos complexos e simples. Dentre outros fatores, está relacionado a comprometimentos na área da atenção compartilhada e limitações na brincadeira simbólica. ${ }^{47}$ Castro $^{48}$ apontou melhorias significativas na capacidade de autorregulação emocional, auxiliando na intensidade da expressão comunicativa, a partir de interações de fazer musical.

A música, bem como as técnicas de musicoterapia vem sendo apontadas como um importante auxílio para o tratamento e cuidado de crianças e adultos portadores de TEA. Sob esse aspecto, Dornelles ${ }^{49}$ indica que a experiência musical pode ocasionar impacto positivo na melhoria dos comportamentos desses indivíduos, quando em contato com o modelo terapêutico. Dentre os benefícios estão: a facilitação da expressão emocional, o desenvolvimento comunicativo, a adaptação e integração social e a aprendizagem de comportamentos de rotina. Esses resultados, de acordo com Fernandes, ${ }^{50}$ estão relacionados ao elemento musical, que torna-se, no processo musicoterapêutico, uma via de comunicação entre o paciente, o musicoterapeuta e demais participantes das sessões.

A música é um meio cujas expressões por ela emanadas permitem o alivio da tensão emocional, superando deste modo as dificuldades da fala e da linguagem. É, igualmente, utilizada para ensinar a controlar a respiração e, nos casos da existência de distúrbios na fala, ajuda a melhorar a dicção. As atividades que se prendem com a musicalização podem ser instrumentos potenciais para servir de estímulo à realização e à organização do pensamento, pois estas atividades sendo realizadas em grupo podem igualmente fomentar a cooperação e comunicação. O envolvimento da criança numa atividade, cujo objetivo é ela própria, onde coopera e em que o seu modo próprio de se expressar é respeitado e a sua forma de agir é consequentemente valorizada, permite desenvolver de um modo crescente a sua própria autoestima. ${ }^{51}$

Em um estudo comparativo entre a aplicação da musicoterapia de improvisação e os cuidados habituais com portadores de TEA, a exemplo de aconselhamento com os pais, observou-se que ambos cuidados promoveram redução nos valores observados no Protocolo de Observação para Diagnóstico de Autismo (PODA), mais especificamente no item "domínio de afeto social". ${ }^{52}$ O PODA é um protocolo que tem o escopo de realizar o diagnóstico do autismo, em base às competências sociais e de comunicação observados pelo experimentador na interação de atividades dirigidas. ${ }^{53}$

\section{CONSIDERAÇÕES FINAIS}

Ainda é pouca a evidência acerca de quais estilos musicais são mais favoráveis a promover saúde em indivíduos portadores do TEA. Contudo, os estudos demonstrem o potencial positivo da aplicação da música nesses indivíduos. Além disso, existe carência de protocolo de aplicação musical, sendo entendida como uma terapia complementar às demais iniciativas, sendo o musicoterapeuta, então, um integrante da equipe multidisciplinar do cuidado desses indivíduos.

Portanto, sugere-se que sejam realizados mais estudos experimentais e de intervenção, visando identificar a correlação entre marcadores comportamentais e também biológicos da eficácia da música com o referido público, testando diferentes estilos musicais. É de conhecimento que a pesquisa de biomarcadores para o diagnóstico e tratamento de TEA ainda é incipiente e está em desenvolvimento, entretanto é um importante e vasto campo de investigação, sobretudo quando o objetivo é aumento da qualidade de vida e a promoção da saúde desses indivíduos. 


\section{REFERÊNCIAS}

1. Mofredj A, Alaya S, Tassaioust K, Bahloul H, Mrabet A. Music therapy, a review of the potential therapeutic benefits for the critically ill. Journal of Critical Care 2016;35(1):195-199. doi: 10.1016/j.jcrc.2016.05.021

2. Brandalise A. Musicoterapia Aplicada à Pessoa com Transtorno do Espectro do Autismo (TEA): uma revisão sistemática. Revista Brasileira de Musicoterapia 2013;15(15):28-42.

3. Geretsegger M, Elefant C, Mössler KA, Gold C. Music therapy for people with autism spectrum disorder. Cochrane Database of Systematic Reviews 2014;17(6):1-64. doi: 10.1002/14651858

4. Whipple J. Music therapy as an effective treatment with Autism Spectrum Disorders in early childhood: A metaanalysis. Journal of Music Therapy 2004;41(2):90-106. doi: https://doi.org/10.1093/jmt/41.2.90

5. Bjorklund G, Saad K, Chirumbolo S, Kern JK, Geier DA, Geier MR, Urbina MA. Immune dysfunction and neuroinflammation in autism spectrum disorder. Acta Neurobiol Exp (Wars) 2016;76(4):257-268

6. Corbett BA, Simon D. Adolescence, stress and cortisol in autism spectrum disorders. OA Autism 2014;1(1):1-9.

7. Onore $C$, Careaga M, Ashwooda P. The role of immune dysfunction in the pathophysiology of autism. Brain, Behavior, and Immunity 2012;26(3):383-392. doi: 10.1016/j. bbi.2011.08.007

8. Markkanen E, Meyer U, Dianov GL. DNA Damage and Repair in Schizophrenia and Autism: Implications for Cancer Comorbidity and Beyond. International Journal of Molecular Sciense, Basel 2016;17(1):1-17. doi: 10.3390/ijms17060856

9. Yui K, Sato A, Imataka G. Mitochondrial Dysfunction and Its Relationship with Signaling and Oxidative Damage in Autism Spectrum Disorders. Mini-Reviews in Medicinal Chemistry 2015;15(5):373-89.

10. Rego SWSE. Autismo: Fisiopatologia e biomarcadores. 46 folhas. Dissertação para obtenção do Grau de Mestre em Medicina. Universidade da Beira Interior, Covilhã, 2012.

11. FancourtD, Ockelford A, Belai A. The psychoneuroimmunological effects of music: a systematic review and a new model. Brain, Behavior, and Immunity 2014;36(1):15-26. doi: 10.1016/j. bbi.2013.10.014

12. Spiroski M, Trajkovski V, Trajkov D, Petlichkovski A, EfinskaMladenovska O, Hristomanova S, Djulejic E, Paneva M, Bozhikov J, Family analysis of immunoglobulin classes and subclasses in children with autistic disorder. Bosnian journal of basic medical sciences 2009;9(4):283-289.

13. Wasilewska J, Kaczmarski M, Stasiak-Barmuta A, Tobolczyk J, Kowalewska E. Low serum IgA and increased expression of CD23 on B lymphocytes in peripheral blood in children with regressive autism aged 3-6 years old. Archives of medical Science 2012;8(2):324-331. doi: 10.5114/ aoms.2012.28561

14. Hisao E. I., Patterson, P. H. Placental Regulation of MaternalFetal Interactions and Brain Development. Developmental Neurobiology 2012;72(10):1317-1326. doi: 10.1002/ dneu. 22045

15. Danese A, Lewis S. Psychoneuroimmunology of Early Life Stress: The Hidden Wounds of Childhood Trauma? Neuropsychopharmacology 2016;42(1):99-114. doi: 10.1038/npp.2016.198

16. Tordjman S, Anderson GM, Kermarrec S, Bonnot O, Geoffray MM, Brailly-Tabard S, Chaouch A, Colliot I, Trabado S, Bronsard G, Coulon N, Botbol M, Charbuy H, Camus F,
Touitou Y. Altered circadian patterns of salivary cortisol in low-functioning children and adolescents with autism. Psychoneuroendocrinology 2014;50(1):227-245. doi: 10.1016/j.psyneuen.2014.08.010

17. Ogawa S, Lee YA, Yamaguchi Y, Shibata Y, Goto Y. Associations of acute and chronic stress hormones with cognitive functions in autism spectrum disorder. Neuroscience 2017;343(1):229-239. doi: 10.1016/j. neuroscience.2016.12.003

18. Rance G, Chisari D, Saunders K, Rault JL. Reducing listeningrelated stress in school-aged children with autism spectrum disorder. Journal of autism and developmental disorders 2017;47(7): 2010-2022. doi: 10.1007/s10803-017-3114-4

19. Thomas P, Harvey S, Gruner T, Fenech M. The buccal cytome and micronucleus frequency is substantially altered in Down's syndrome and normal ageing compared to young healthy controls. Mutation Research 2008;638(1):37-47. doi: 10.1016/j.mrfmmm.2007.08.012

20. François M, Leifert W, Hecker J, Faunt J, Martins R, Thomas $\mathrm{P}$, Fenech M. Altered cytological parameters in buccal cells from individuals with mild cognitive impairment and Alzheimer's disease. Cytometry 2014;85(8). doi: 10.1002/ cyto.a. 22453

21. Lee SL, Thomas P, Hecker J, Faunt J, Fenech M. Chromosomal DNA damage measured using the cytokinesis-block micronucleus cytome assay is significantly associated with cognitive impairment in South Australians. Environmental and Molecular Mutagenesis 2015;56(1):32-40. doi: 10.1002/ em. 21890

22. Main PA, Thomas P, Esterman A, Fenech MF. Necrosis is increased in lymphoblastoid cell lines from children with autism compared with their non-autistic siblings under conditions of oxidative and nitrosative stress. Mutagenesis 2013;28(4):475-484. doi: 10.1093/mutage/get025

23. Andrés-García S, Moya-Albiol L, González-Bono. Salivary cortisol and immunoglobulin A: Responses to stress as predictors of health complaints reported by caregivers of offspring with autistic spectrum disorder. Hormones and Behavior 2012;62(4):464-474. doi: 10.1016/j. yhbeh.2012.08.003

24. Klein J, Ackerman SL. Oxidative stress, cell cycle, and neurodegeneration. The Journal of Clinical Investigation, Ann arbor 2003;111(6):785-793. doi: 10.1172/JCl18182

25. Deth R, Muratore C, Benzecry J, Power-Charnitsky VA, Waly M. How environmental and genetic factors combine to cause autism: a redox/methylation hypothesis. Neurotoxicology 2008;29(1):190-201. doi: 10.1016/j.neuro.2007.09.010

26. Rúpolo BS, Mira JGS, Kantor Júnior O. Deficiência de IgA. Jornal de Pediatria, Rio de Janeiro 1998;74(6):433-440.

27. Ghazali DA, Darmian-Rafei I, Nadolny J, Sosner P, Ragot S, Oriot D. Evaluation of stress response using psychological, biological, and electrophysiological markers during immersive simulation of life threatening events in multidisciplinary teams. Australian Critical Care 2017;30(4). doi: 10.1016/j. aucc. 2017.07.001

28. Helhammer DH, Wüst S, Kudielka BM. Salivary cortisol as a biomarker in stress research. Psychoneuroendocrinology, Toulouse 2009;34(2):163-171. doi: 10.1016/j. psyneuen.2008.10.026

29. Faro A, Pereira ME. Medidas do estresse: uma revisão narrativa. Psicologia, Saúde \& Doença 2013;14(1):101-124.

30. El-Farhan N, Rees DA, Evans C. Measuring cortisol in serum, urine and saliva - are our assays good enough? Annals of Clinical Biochemistry 2017;54(3): 308-322. doi: 


\section{$10.1177 / 0004563216687335$}

31. Bolognesi C, Roggieri P, Ropolo M, Thomas P, Hor M, Fenech M, Nersesyan A, Knasmueller S. Buccal micronucleus cytome assay: results of an intra - and inter -laboratory scoring comparison. Mutagenesis 2015;30(4):545-555. doi: 10.1093/mutage/gev017

32. Rohr P, Silva J, Silva F, Sarmento M, Porto C, Debastiani R, Santos CEI, Dias JF, Kvitko K. Evaluation of genetic damage in open-cast coal mine workers using the buccal micronucleus cytome assay. Environmental and Molecular Mutagenesis 2013;54(1):65-71. doi: 10.1002/em.21744

33. Bolognesi C, Bonassi S, Knasmueller S, Fenech M, Bruzzone M, Lando C, Ceppi M. Clinical application of micronucleus test in exfoliated buccal cells: a systematic review and metanalysis. Mutat Res Rev Mutat Res 2015;766:20-31. doi: 10.1016/j.mrrev.2015.07.002

34. Torres-Bugarín O, Pacheco-Gutiérrez AG, Vázquez-Valls E, Ramos-lbarra ML, Torres-Mendoza BM. Micronuclei and nuclear abnormalities in buccal mucosa cells in patients with anorexia and bulimia nervosa 2014;29(6):427-31. doi: 10.1093/mutage/geu044

35. León-Mejía G, Quintana M, Debastiani R, Dias J, Espitia-Pérez L, Hartmann A, Pêgas HJA, Da Silva J. Genetic damage in coal miners evaluated by buccal micronucleus cytome assay. Ecotoxicology and Environmental Safety 2014;107(1):133139. doi: 10.1016/j.ecoenv.2014.05.023

36. Nadak R, Schumacher B. DNA Damage Response and Immune Defense: Links and Mechanisms. Frontiers in Genetics 2016;7(1):1-10. doi: https://doi.org/10.3389/ fgene.2016.00147

37. Charnetski CJ, Brennan FX. Effect of music and auditory stimuli on secretory immunoglobulin A (IgA). Perceptual and Motor Skills 1998;87(1):1163-1170. doi: 10.2466/ pms.1998.87.3f.1163

38. Hirokawa $\mathrm{E}$, Ohira $\mathrm{H}$. The effects of music listening after a stressful task on immune functions, neuroendocrine responses, and emotional states in college students. Journal of Music Therapy, Silverspring 2003;40(3):189-211.

39. De la Rubia Ortí JE, García-Pardo MP, Cabañés Iranzo C, Cerón Madrigal JJ, Castillo SS, Julián Rochina M, Prado Gascó VJ. Does music therapy improve anxiety and depression in alzheimer's patients? The Journal of Alternative and Complementary Medicine. 2017. ahead of print. doi: 10.1089/acm. 2016.0346

40. Pegoraro LC. A música como intervenção neuropsicológica no tratamento do Transtorno do Espectro Autista (TEA): Uma visão crítica da literatura. Artigo apresentado como exigência parcial do Curso de Especialização em Psicologia. Universidade Federal do Rio Grande do Sul, Porto Alegre, 2017.

41. Goldstein EB. Sensation \& Perception. 7. ed. Belmont: Wadsworth, 2007

42. Kandel ER, Schwartz JH, Jessell TM. Princípios da neurociência. 4. ed. Barueri: Manole, 2003.
43. Levitin DJ. A música no seu cérebro: A ciência de uma obsessão humana. Rio de Janeiro: Civilização Brasileira, 2010.

44. Schiffman HR. Sensação e Percepção. 5. ed. Rio de Janeiro: LTC, 2005.

45. Silva JA, Galdino MKC, Gadelha, MJN, Andrade MJO, Santos, NA. Revisão sobre o processamento neuropsicológico dos atributos tonais da música no contexto ocidental. Avances en Psicología Latinoamericana 2013;31(1):86-96.

46. Careaga $M$, Murai, $T$; Bauman M. D. Maternal Immune Activation and Autism Spectrum Disorder: From Rodents to Nonhuman and Human Primates. Biological Psychiatry 2017;81(5):391-401. doi: 10.1016/j.biopsych.2016.10.020

47. Marques DF, Bosa CA. Protocolo de Avaliação de Crianças com Autismo: Evidências de Validade de Critério. Psicologia: Teoria e Pesquisa 2015;31(1):43-51. doi: 10.1590/010237722015011085043051

48. Castro, MTLA. Afinar a relação: a musicoterapia e a perturbação no espectro do autismo. 116 folhas. Relatório de estágio apresentado ao Instituto de Psicologia e Ciências da Educação da Faculdade de Ciências Humanas e Sociais da Universidade Lusíada de Lisboa para a obtenção do grau de Mestre em Musicoterapia. Universidade Lusíada de Lisboa, Liboa, 2016.

49. Dornelles LLE. Do silêncio ao som: As musicoterapia no tratamento de crianças com transtorno do espectro autista. Trabalho de conclusão de curso para obtenção do Grau de Bacharel em Psicologia. Universidade Regional do Noroeste do Rio Grande do Sul, Santa Rosa, 2016.

50. Fernandes PRS. Sons e Silêncios: Musicoterapia no tratamento de indivíduos com perturbações do espectro do autismo. Dissertação para obtenção do Grau de Mestre em Ciências da Educação. Universidade Católica Portuguesa, Braga, 2012.

51. Paredes SSG. O papel da musicoterapia no desenvolvimento cognitivo nas crianças com perturbação do espectro autismo. Dissertação para obtenção do Grau de Mestre em Ciências da Educação. Escola Superior de Educação Almeida Garrett, Lisboa, 2012.

52. Bieleninik L, Geretsegger M, Mössler K, Assmus J, Thompson G, Gattino G, Elefant C, Gottfried T, Igliozzi R, Muratori F, Suvini F, Kim J, Crawford MJ, Odell-Miller H, Oldfield A, Casey Ó, Finnemann J, Carpente J, Park AL, Grossi E, Gold C; TIME-A Study Team. Effects of Improvisational Music Therapy vs Enhanced Standard Care on Symptom Severity Among Children With Autism Spectrum Disorder The TIME-A Randomized Clinical Trial. Journal of the American Medical Association 2017;318(6):525-535. doi: 10.1001/ jama.2017.9478

53. Le Couteur A, Rutter M, Lord C, Rios P, Robertson S, Holdgrafer M, McLennan J. Autism diagnostic interview: a standardized investigator-based instrument. Journal of autism and developmental disorders 1989;19(3):363-87.

Como citar: FIOREZI, Juliane Neves et al. Os efeitos da música em biomarcadores de estresse, imunológicos e comportamentais em portadores do espectro autista. Cinergis, Santa Cruz do Sul, v. 18, dez. 2017. ISSN 2177-4005. Disponível em: < https:// online.unisc.br/seer/index.php/cinergis/article/view/11174>. Acesso em: 16 jan. 2018. doi:http://dx.doi.org/10.17058/cinergis. v18i0. 11174 